\title{
The American Journal of Cardiology \\ Socioeconomic Status and Differences in the Management and Outcomes of 6.6 Million US patients with Acute Myocardial Infarction

\author{
--Manuscript Draft--
}

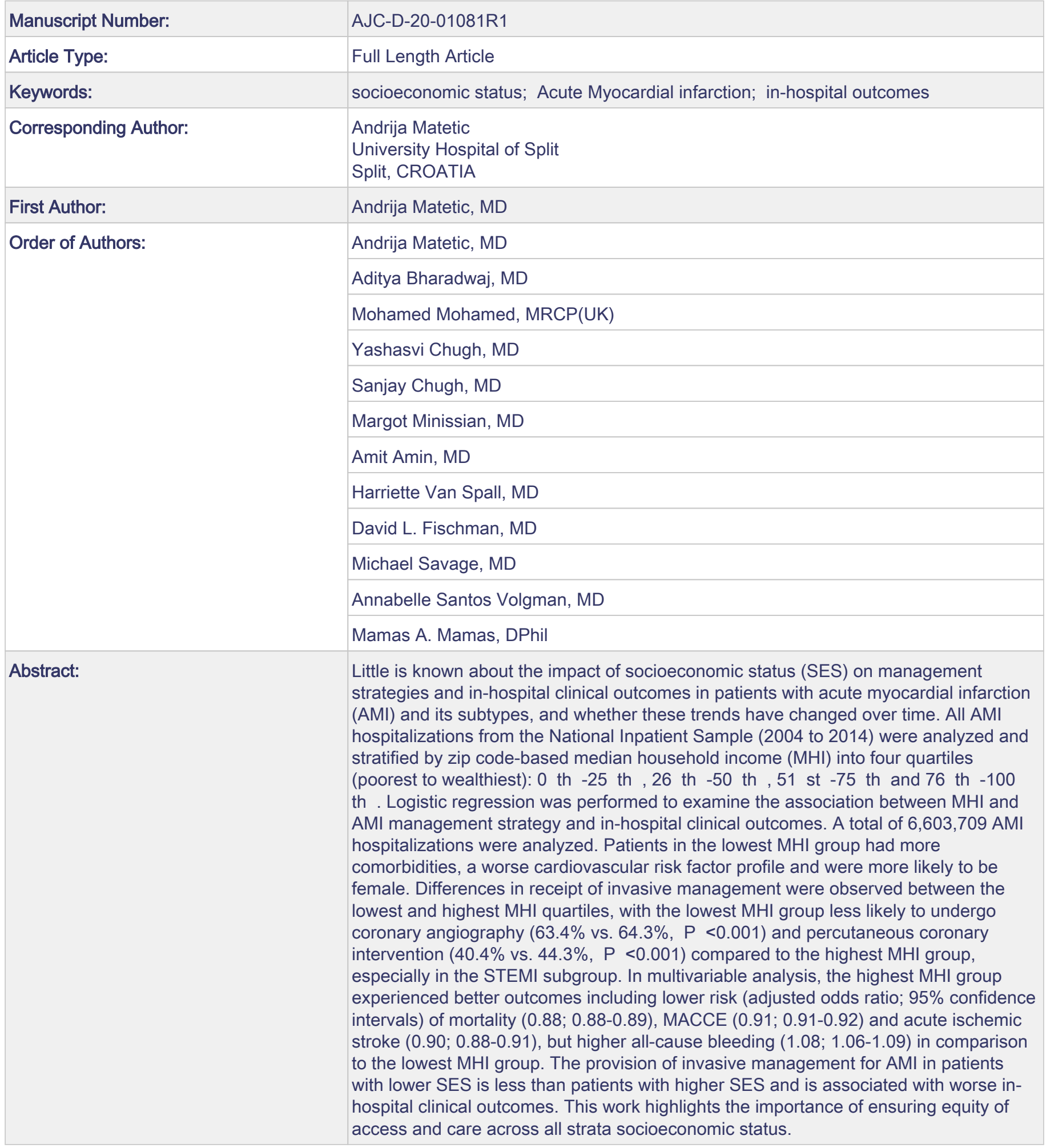


Dear Dr William C. Roberts, Editor-in-Chief

Please find enclosed our revised manuscript entitled 'Socioeconomic Status and Differences in the Management and Outcomes of 6.6 Million US patients with Acute Myocardial Infarction' for consideration for publication in the American Journal of Cardiology.

Acute myocardial infarction (AMI) is the leading cause of mortality in the United States and worldwide. Overall, cardiovascular mortality has improvement in recent years due to a multitude of factors including better recognition and management of cardiovascular risk factors as well as advances in the management of AMI through timely coronary revascularization and adequate secondary preventative therapy.

Socioeconomic status (SES) is increasingly recognized as being an important determinant of cardiovascular health. While lower socioeconomic class has been previously linked to worse clinical outcomes after AMI, previous studies were subject to several limitations such as the inclusion of specific cohorts (e.g. ST-segment elevation myocardial infarction (STEMI) only or elderly patients) or were limited to single center analyses (modest sample size). More importantly, it is unclear whether their worse outcomes are attributed to differences in their receipt of invasive management for their AMI, in the form of coronary angiography (CA) and percutaneous coronary intervention (PCI), if indicated.

The present study examined the trends of management strategies and in-hospital clinical outcomes of AMI according to SES in more than 6.5 million over a 11-year period. We show that lower SES is associated with a greater comorbidity burden. Further, we observe a direct relationship between SES and receipt of invasive management, with higher SES patients more likely to receive coronary angiography and PCI, especially in the STEMI subgroup, even after adjustment for differences in baseline characteristics. Patients with higher SES had better outcomes, including MACCE, mortality and acute stroke, but no difference in bleeding. The observed differences in management and outcomes between SES classes partially improved in later years.

We believe the present study would be of great interest to the readers of the American Journal of Cardiology as it highlights the current SES disparities in receipt of management of 
AMI and subsequently worse outcomes and emphasizes the importance of applying guidelinerecommended management irrespective of SES.

The authors confirm this manuscript is submitted for publication to the American Journal of Cardiology as an original article. Neither the entire paper nor any of its contents is currently being submitted or has been accepted by any other journal. We also confirm that the authors meet the criteria for authorship, namely (1) substantial contributions to conception or design of the work, or the acquisition, analysis, or interpretation of data for the work; and (2) drafting of the work or revising it critically for important intellectual content; and (3) final approval of the version to be published; and (4) agreement to be accountable for all aspects of the work. Finally, the authors confirm that there are no relationships with industry or financial associations that might pose a conflict of interest in connection with this submitted article.

We thank you for your consideration.

We thank you for your consideration.

Yours Sincerely



Prof Mamas A. Mamas

on behalf of all submitting authors 


\section{$\underline{\text { Editor-in-Chied and Editorial Office comments }}$}

1: Respond to the comments of each of the 2 reviewers by revising your manuscript appropriately.

2: Shorten your manuscript during its revision from its present 14.8 to no more than 10.5 text pages (those before the references but including the Title page).

3: Incorporate my editorial changes into your revision (See copy marked "WCR" to be found under 'Action Links' 'Manage Review Attachments.').

4: Try not to repeat data in the tables again in the text.

5: Correct the technical deficiencies (see below) to avoid having your manuscript returned for further revision.

6: Please number the pages of your manuscript with the Title page being 1 . The corresponding author should be put on the title page. A list of abbreviations is not used in the "AJC". Your introduction should be reduced to a 1/2-page single paragraph. Your 4.8 page discussion should be reduced to no more than 3.0 pages.

7: Your tables can be improved (see copy marked "WCR"): your tables should be typed double spaced; the percent sign in the variable column should be eliminated and placed within the parentheses in each numeral column where appropriate in all tables; in table 1 "dyslipidemia" should be defined in a footnote. Thank you.

8: Before returning your revision, please proof it carefully to ensure that: all technical requirements have been met; all reference citations are cited in numerical order within the text and match up correctly with the reference list; all tables and/or figures are cited within the text of the article and are cited in numerical order.

Response: Thank you, all of the above has been implemented. 


\section{$\underline{\text { Reviewers' comments }}$}

\section{$\underline{\text { Reviewer \#1: }}$}

Remark 1: At the STEMI group, only 58\% 65.5\% patients received PCI and 7.4\% 7.9\% patients with CABG therapy, so I suggest to add some data of remaining patients received whether thrombolysis or conservative therapy.

Response 1: Thank you for your comment. We have added the receipt of thrombolysis in the Table 2, including the rates in the total cohort, NSTEMI subgroup and STEMI subgroup. The rate of thrombolysis in the total AMI cohort were $0.4 \%$ vs. $0.4 \%$ vs. $0.5 \%$ vs. $0.6 \%$ (p<0.001) across the Median Household Income categories, respectively.

Remark 2: Optimal medical treatment may affect the outcomes, so I recommend to supplement some data of medical therapy, such as aspirin, P2Y12 inhibitors, ACE inhibitors, ARB, $\beta$-blocks, statins, NOAC, and so on.

Response 2: Thank you for your suggestion. Unfortunately, the National Inpatient Sample database does not capture details on pharmacological therapy. However, we have acknowledged these in out limitations. Notwithstanding, secondary prevention therapy is more likely to affect long-term ischemic outcomes, but we recognise that differences in inhospital major bleeding events rates may be influenced by the rate of utilization of antithrombotic therapy across comorbidity groups.

Remark 3: IABP may not be helpful to patients with cardiogenic shock, but other assist device may be useful, so I suggest to supplement some data of which kinds of assist device used.

Response 3: We have used ICD-9 codes 37.61 and 37.68 to define the use of "left ventricular assist device or IABP" as indicated in the Supplementary Table S1 and this was adjusted for in our analysis. These codes are defined in the ICD manual as follows: 1) the implantation of pulsation balloon (IABP) [code 37.61] and 2) insertion of percutaneous external heart assist device [code 37.68]. The codes do not tell us which specific assist device was used but this is frequently the case in studies following a similar design to ours.

Remark 4: Reperfusion time is very important for the STEMI, so I hope to add some time information, such as the onset of chest pain, door to balloon time (DTB) for PCI, and so on. 
Response 4: Unfortunately, the NIS database does not provide information on the timing of procedures.

\section{Reviewer 2:}

Remark 1 (Results): The authors revealed that some differences were observed in patients background. However, some of these differences were very tiny, although these differences were statistically significant. Please comment what is clinical implication of these small differences.

Response 1: Thank you for your observation. We thank the reviewer for their comment and fully agree that with large sample sizes, even the smallest comparisons can appear statistically significant, but this does not necessarily confer clinical significance. This is why we have chosen to focus on the effect size than clinical significance for our comparisons across median household groups, especially when reporting our main outcomes, namely mortality, bleeding and acute stroke.

Remark 2 (Discussion): In addition to increasing rate of invasive management, are there other possibilities to increase bleeding events?

Response 2: It is possible that the increased use of more potent antithrombotic medications over have accounted for the increased bleeding events the years. Furthermore, higher comorbidity burden has been related to higher bleeding rates. Unfortunately, the lack of data on the specific pharmacologic management in the National Inpatient Sample dataset prevents us from further analyses. Nevertheless, we have added an additional explanatory sentence in the Discussion section of the manuscript.

Remark 3 (Discussion): The authors mentioned aggressive primary prevention would be required to improve outcomes of low SES group. Would it be possible to perform such aggressive prevention without universal health care system? The authors should discuss what should we do for primary prevention.

Response 3: Thank you for your comment. Studies from other countries with a universal healthcare system have shown a greater equity in delivery of healthcare based on socioeconomic status as we have discussed in the manuscript. However the authors believe that in the absence of universal health care other aggressive measures are required to bridge the gap between SES groups. The US Federal Healthy People initiative is one such measure to 
ensure equitable primary care access and bridge the gap. We have modified the Discussion to enumerate the basic framework of the Healthy People initiative. Additionally we have also included some possible measures that could be undertaken for primary prevention at a physician-level. 
Socioeconomic Status and Differences in the Management and Outcomes of 6.6

\section{Million US patients with Acute Myocardial Infarction}

Running title: Socioeconomic status impact on AMI outcomes

Andrija Matetic, $\mathrm{MD}^{\mathrm{a}^{*}}$, Aditya Bharadwaj, $\mathrm{MD}^{\mathrm{b} *}$, Mohamed Mohamed, MRCP(UK) $)^{\mathrm{c}, \mathrm{d}}$, Yashasvi Chugh, $\mathrm{MD}^{\mathrm{e}}$, Sanjay Chugh, MD ${ }^{\mathrm{f}}$, Margot Minissian, $\mathrm{MD}^{\mathrm{g}}$, Amit Amin, $\mathrm{MD}^{\mathrm{h}}$, Harriette Van Spall, MD ${ }^{\mathrm{i}}$, David L. Fischman, MD', Michael Savage, MD ${ }^{\mathrm{j}}$, Annabelle Santos Volgman ${ }^{\mathrm{k}}$, Mamas A. Mamas, DPhil ${ }^{\mathrm{c}, \mathrm{d}, \mathrm{j}}$

(a) Department of Cardiology, University Hospital of Split, Split, Croatia

(b) Loma Linda University Medical Center, Loma Linda, CA, USA

(c) Keele Cardiovascular Research Group, Centre for Prognosis Research, Keele University, UK

(d) Department of Cardiology, Royal Stoke University Hospital, Stoke-on-Trent, UK

(e) Mount Sinai St Luke's - Roosevelt Hospital, New York, NY, USA

(f) Jaipur National University Hospital and Medical College, IMSRC, Jaipur, Rajasthan, India

(g) Barbara Streisand Women's Heart Center, Smidt Heart Institute, Cedars-Sinai Medical Center, Los Angeles, USA

(h) Washington School of Medicine, St. Louis, Missouri

(i) Department of Medicine, McMaster University, Hamilton, ON, Canada; Population Health Research Institute, Hamilton, ON, Canada

(j) Department of Medicine (Cardiology), Thomas Jefferson University Hospital, Philadelphia, Pennsylvania

(k) Department of Medicine, Section of Cardiology, Rush Medical College, Chicago, USA

\section{*Both authors contributed equally - joint first authors}

Correspondence to:

Mamas A. Mamas

Professor of Cardiology

Keele Cardiovascular Research Group,

Centre for Prognosis Research,

Institute for Primary Care and Health Sciences,

Keele University, UK

mamasmamas1@yahoo.co.uk 


\section{Abstract:}

Little is known about the impact of socioeconomic status (SES) on management strategies and in-hospital clinical outcomes in patients with acute myocardial infarction (AMI) and its subtypes, and whether these trends have changed over time. All AMI hospitalizations from the National Inpatient Sample (2004 to 2014) were analyzed and stratified by zip code-based median household income (MHI) into four quartiles (poorest to wealthiest): $0^{\text {th }}-25^{\text {th }}, 26^{\text {th }}-50^{\text {th }}, 51^{\text {st }}-75^{\text {th }}$ and $76^{\text {th }}-100^{\text {th }}$. Logistic regression was performed to examine the association between MHI and AMI management strategy and in-hospital clinical outcomes. A total of 6,603,709 AMI hospitalizations were analyzed. Patients in the lowest MHI group had more comorbidities, a worse cardiovascular risk factor profile and were more likely to be female. Differences in receipt of invasive management were observed between the lowest and highest MHI quartiles, with the lowest MHI group less likely to undergo coronary angiography $(63.4 \%$ vs. $64.3 \%, P<0.001)$ and percutaneous coronary intervention (40.4\% vs. $44.3 \%, P<0.001)$ compared to the highest MHI group, especially in the STEMI subgroup. In multivariable analysis, the highest MHI group experienced better outcomes including lower risk (adjusted odds ratio; 95\% confidence intervals) of mortality $(0.88 ; 0.88-0.89)$, MACCE $(0.91 ; 0.91-0.92)$ and acute ischemic stroke $(0.90$; 0.88-0.91), but higher all-cause bleeding $(1.08 ; 1.06-1.09)$ in comparison to the lowest MHI group. In conclusion, the provision of invasive management for AMI in patients with lower SES is less than patients with higher SES and is associated with worse in-hospital clinical outcomes. This work highlights the importance of ensuring equity of access and care across all strata socioeconomic status.

Key words: socioeconomic status; acute myocardial infarction; in-hospital outcomes. 


\section{Introduction:}

Lower socioeconomic status (SES) has been previously linked to higher prevalence of traditional cardiovascular risk factors ${ }^{1}$, increased burden of $\mathrm{CAD}^{2}$ and higher mortality. ${ }^{3}$ Of the individual components of SES, median household income (MHI) has been shown to be a surrogate of SES for the purpose of health research. ${ }^{4,5}$ Although previous studies have evaluated the relationship between SES and management strategy or in-hospital outcomes in the context of acute myocardial infarction (AMI), the findings have been subject to limitations such as the inclusion of specific cohorts (e.g. ST-segment elevation myocardial infarction (STEMI) only or elderly patients) $)^{6-8}$, or were limited to single center analyses. ${ }^{9}$ More importantly, there is a lack of temporal data of how disparities in management and outcomes of AMI attributable to SES have changed over time. In this study we sought to evaluate the association of SES, as measured by MHI, on receipt of invasive management and subsequent in-hospital clinical outcomes in a nationwide cohort of AMI hospitalizations in the United States (US) over an 11-year period.

\section{Methods}

The National Inpatient Sample (NIS) is the largest publicly available all-payer database of hospitalized patients in the US and is sponsored by the Agency for Healthcare Research and Quality (AHRQ). ${ }^{10}$ It includes anonymized data on discharge diagnoses and procedures from $>7$ million hospitalizations annually. The NIS dataset was designed to approximate a $20 \%$ stratified sample of US community hospitals and provides sampling weights to calculate national estimates that represent $>95 \%$ of the US population.

All non-elective hospitalizations of adults ( $\geq 18$ years) discharged between 2004 and 2014 with a principal diagnosis of AMI (STEMI and non-STEMI (NSTEMI)) were extracted from the NIS using the International Classification of Diseases, Ninth revision 
(ICD-9) and Clinical Classification Software (CCS) codes (Supplementary Table S1). Additional comorbidities were identified using AHRQ-Elixhauser comorbidity measures. Charlson Comorbidity Index (CCI) was extracted using the variables according to the Deyo modification of the score as previously described. ${ }^{11}$ Patient characteristics and in-hospital clinical outcomes were stratified according to MHI quartiles in 4 groups: $0^{\text {th }}-25^{\text {th }}, 26^{\text {th }}-50^{\text {th }}$, $51^{\text {st }}-75^{\text {th }}$ and $76^{\text {th }}-100^{\text {th }}$, indicating the poorest to the wealthiest groups, respectively (Supplementary Table S2). Missing records for length of stay and total charges were excluded from further analysis (Supplementary Figure S1).

We analyzed the database for receipt of in-hospital invasive management (coronary angiography, percutaneous coronary intervention (PCI) and coronary artery bypass grafting $(\mathrm{CABG}))$ for $\mathrm{AMI}$ between different incomes groups. Subsequent in-hospital clinical outcomes including major acute cardiovascular and cerebrovascular events (MACCE), mortality, cardiac complications and acute stroke were assessed for differences among income groups. MACCE was defined as a composite of mortality, acute stroke/transient ischemic attack (TIA) and cardiac complications. Cardiac complications included hemopericardium, cardiac tamponade, coronary dissection and any pericardiocentesis procedure.

Statistical Package for the Social Sciences (SPSS) statistical software (IBM Corp, Armonk, NY; version 25) was used for statistical data analysis. We assessed the normality of data distribution graphically and by the Kolmogorov-Smirnov test. Data were expressed as median (interquartile range) for continuous variables and as whole numbers (percentages) for categorical variables. Mann-Whitney U test and Kruskal-Wallis test have been used for comparison of quantitative non-parametric variables between the study 
groups. The Chi-square test was used for the comparison of categorical variables between the different groups according to MHI.

Multivariable logistic regression analysis was used to determine the adjusted odds ratios (aOR [95\% confidence interval]) of in-hospital adverse outcomes and the likelihood of an invasive management strategy, according to the different MHI groups in comparison to patients with the MHI in the lowest $\left(0^{\text {th }}-25^{\text {th }}\right)$ quartile as a reference. Separate models for in-hospital clinical outcomes and invasive management were conducted. Regression models for in-hospital clinical outcomes included PCI as a predictor variable. As well, the following variables were adjusted for in regression analysis: age, sex, weekend admission, dyslipidemia, smoking, previous AMI, previous $\mathrm{CABG}$, history of ischemic heart disease (IHD), previous PCI, previous cerebrovascular accident, family history of coronary artery disease (CAD), shock during hospitalization, hospital bed size, hospital region, location/teaching status of hospital, year of hospitalization and 27 AHRQ comorbidities (acquired immune deficiency syndrome, alcohol abuse, deficiency anemias, chronic blood loss anemia, rheumatoid arthritis/collagen vascular diseases, congestive heart failure, chronic pulmonary disease, coagulopathy, diabetes (uncomplicated), diabetes with chronic complications, drug abuse, hypertension, hypothyroidism, liver disease, lymphoma, fluid and electrolyte disorders, metastatic cancer, other neurological disorders, obesity, paralysis, peripheral vascular disorders (PVD), pulmonary circulation disorders, renal failure, solid tumor without metastasis, peptic ulcer disease excluding bleeding, valvular heart disease and weight loss). Using a Bonferroni's correction method, threshold of significance for the regression model has been set to $\mathrm{p}<0.001$. A trend analysis with a Mantel-Haenszel test of trend (linear-by-linear association) was conducted in order to 
establish important changes in in-hospital outcomes and receipt of invasive management over the 11-year time period. Statistical significance was defined at a level of $\mathrm{p}<0.05$.

\section{Results}

A total of 6,603,709 hospitalizations for AMI were included in the analysis. The distribution of patients according to $\mathrm{MHI}$ quartile was as follows: $0^{\text {th }}-25^{\text {th }}: 28.5 \%$ $(\mathrm{N}=1,884,699), 25^{\text {th }}-50^{\text {th }}: 27.4 \%(\mathrm{~N}=1,806,775), 51^{\text {st }}-75^{\text {th }}: 23.7 \%(\mathrm{~N}=1,567,720)$ and $76^{\text {th }}-$ $100^{\text {th }}: 20.4 \%(\mathrm{~N}=1,344,515)$, indicating poorest to wealthiest, respectively (Table 1).

The median age range was similar across MHI groups (67-69 years), whereas in the lower MHI subgroups females comprised a higher percentage $(42.0 \%$ to $37.4 \%, P<0.001)$. STEMI prevalence ranged from $34.2 \%-35.4 \%$ with the highest rates found in the third quartile MHI group $\left(51^{\text {st }}-75^{\text {th }}\right)$. An inverse relationship between MHI quartile and comorbidity burden was observed across the groups, as measured by CCI score and overall comorbidity prevalence $(P<0.001)$. The lowest MHI group was more commonly treated in large hospitals than higher MHI quartiles (67.9\% vs. $65.7 \%$ vs. $64.1 \%$ vs. $62.4 \%, P<0.001)$. Furthermore, only $1.1 \%$ of high MHI patients were treated in rural hospitals compared to $19.4 \%$ of lowest MHI group $(P<0.001)$ (Table 1$)$, and had significantly higher total charges of hospitalization (40,939 vs. 41,208 vs. 44,639 vs. 47,676 USD, $P<0.001$ ) (Table 2).

The lowest MHI group was less likely to undergo coronary angiography (63.4\% vs. $64.3 \%-65.7 \%, P<0.001)$ and PCI (40.4\% vs. $42.7 \%-44.8 \%, P<0.001)$ (Table 2, Figure 1). In contrast, the wealthiest group was less likely to undergo CABG (8.5\% vs. $8.9 \%$ 9.1\%, $P<0.001$ ) (Table 2). These differences persisted irrespective of the AMI subtype, except for the coronary angiography which was the least utilized in NSTEMI patients from the highest MHI group (57.8\% vs. 59.7\% - 60.1\%, $P<0.001)$. 
After adjustment for baseline differences, the highest MHI group had greater odds of receipt of PCI (aOR $1.10[1.10,1.11])$ in comparison to the lowest income group (Table $3)$, irrespective of the AMI subtype $(P<0.001)$ (Table 4). On the other hand, odds of receipt of coronary angiography have been dependent on AMI subtype, showing lower odds in NSTEMI and higher odds in STEMI patients from the highest MHI group (Table 4).

The highest MHI subgroup experienced the lowest MACCE, mortality and acute stroke rates $(P<0.001)$. In contrast, all-cause bleeding and receipt of circulatory support (left-ventricle assist device [LVAD] and intra-aortic balloon pump [IABP]) were more commonly observed in the highest MHI group. In sensitivity analysis, these differences declined in the NSTEMI subgroup for the MACCE outcome, but remained in other outcomes irrespective of the AMI subtype. Differences were generally more pronounced in the STEMI subgroup (Table 2).

The findings persisted in multivariable analysis, in which the highest MHI group had the lowest odds of MACCE (aOR $0.91[0.91,0.92])$, mortality (aOR $0.88[0.88,0.89])$ and acute stroke/TIA (aOR $0.90[0.88,0.91])$ (Table 3). This pattern was found in both STEMI and NSTEMI subgroups (Table 4).

Overall receipt of coronary angiography or PCI steadily increased over the years, irrespective of MHI (Table 5). Graphical analysis of adjusted odds for invasive management has shown a constant pattern of MHI-related disparity in coronary angiography and PCI receipt, but recent years suggest alleviation of such inequalities. This tendency has been observed for PCI in both AMI subgroups, while receipt of coronary angiography has shown a convergent trend only in STEMI patients (Figure 2, Supplementary Table S3-S5). Likewise, outcome inequalities among different MHI groups exist but generally tended to decrease in recent years, except for mortality which maintains 
a divergent trend in both AMI subgroups (Figure 3, Supplementary Table S3-S5). Trend analysis revealed a significant decline in all adverse outcomes across the years, except allcause bleeding which showed a steady increase, in all MHI groups (Table 5).

\section{Discussion:}

The present study of $>6.5$ million hospitalizations is by far the largest to examine the trends of management strategies and in-hospital clinical outcomes of AMI according to SES over a 11-year period. Several key findings can be noted. First, we show that SES is associated with comorbidity burden, with a lower overall comorbidity burden found in the higher SES groups. Second, we observe a direct relationship between SES and invasive management, with higher SES patients more likely to receive coronary angiography and PCI. Patients with higher SES had better outcomes, including MACCE, mortality and acute stroke, but not bleeding. Notwithstanding, these inequalities have considerably improved over the study period, although not fully resolved.

Our analysis reveals that AMI patients with low SES generally have more comorbidities compared to their high SES counterparts, consistent with previous reports. ${ }^{6,7,12-14}$ Whilst significant differences among AMI patients based on SES in terms of management and outcomes were observed, these substantially lessened over time. An improvement in mortality with an increase in bleeding rates was observed in all MHI groups over the study period. These trends could partly be attributable to higher overall use of invasive management, but other factors like potent antithrombotic therapy could presumably also affect bleeding rates. ${ }^{15}$ Previous studies that have evaluated the impact of SES on outcomes of AMI are smaller ${ }^{16}$, included only STEMI patients ${ }^{7}$ or elderly patients ${ }^{8}$ or occurred in healthcare settings outside of the US. ${ }^{6,12}$ Yong et al evaluated acute coronary syndrome patients $(\mathrm{N}=835,070)$ and found that low SES patients were least likely to get 
timely revascularization and DES. ${ }^{16}$ Agarwal et al analyzed NIS data of STEMI patients (2003-2011) reporting that lower SES patients had decreased timely reperfusion and increased in-hospital mortality. ${ }^{7}$ Rao et al evaluated elderly American Medicare beneficiaries in the angioplasty era concluding that there were significant disparities in management and outcomes based on SES. ${ }^{8}$ Interestingly, studies performed in countries offering universal healthcare systems have shown less disparity in delivery of healthcare based on SES. ${ }^{6,12,17}$ An Australian study of STEMI patients (2005-2015) treated at 6 government funded hospitals $(\mathrm{N}=5,665)$ reported that even though lower SES was associated with more comorbidities and slightly longer reperfusion times, there was no difference in in-hospital and 1-year mortality and MACE (composite of death, AMI, and target vessel revascularization). ${ }^{6}$ However a Swiss study of 10,895 AMI patients (19952013) revealed that patients residing in low SES areas had worse outcomes with differences persisting even after adjusting for traditional risk factors. ${ }^{18}$

The reasons for lower adoption of evidence-based management and the poor outcomes among low SES AMI patients are complex and multifactorial. Lack of education and social awareness, poor access to transport and specialized care hospitals and lack of insurance places low SES patients at a disadvantage. ${ }^{5}$ Even when they do receive invasive therapy low SES patients with AMI have longer reperfusion times ${ }^{7}$, and are less likely to receive $\mathrm{DES}^{16}$ and to be prescribed guideline directed medical therapy at follow up. ${ }^{6}$

This is the largest study to date to analyze in-hospital outcomes of AMI patients based on SES from a national perspective. Our analysis emphasizes the importance of continued public health measures to aid screening and prevention in low SES groups. The World Health Organization's "25by 25 " initiative aims to reduce cardiovascular mortality by $25 \%$ by year 2025 irrespective of any socioeconomic, racial or gender-based 
differences. ${ }^{19}$ Universal health care, which will enable equal access to primary care services, has been recognized as a step towards sustainable development and diminishing inequalities. ${ }^{20}$. In the absence of universal health care other measures such as the US Federal Government's Healthy People initiative are imperative. This initiative aims to provide data and tools to eliminate disparities in healthcare access and delivery based on sex, age, race, region and SES. A five-step framework for public health intervention called MAP-IT (mobilize, assess, plan, implement and track) has been recommended as a path to the establishment of a healthy community. ${ }^{21}$ Additionally at a physician-level, outreach services to lower SES communities, mass screening initiatives and raising public awareness through media campaigns should be considered.

We acknowledge several limitations of our study, including the utilization of zip code based MHI as a surrogate for SES. Although we do not take into account other SES components such as education and employment as has been defined in expert documents ${ }^{5}$, the sole utilization of zip code based income is a well-established method within healthcare systems $^{22,23}$. Secondly, some limitations like coding errors, hospitalization-based data, under-reporting of secondary diagnoses and lack of formal adjudication of outcomes are inherent to the NIS database itself. ${ }^{15}$ The NIS also does not capture the exact cause of death, and long-term outcomes thereby limiting us to just in-hospital events. Finally the NIS does not capture antithrombotic strategies or drug therapies that may confound our findings.

In conclusion, using zip-code based SES, patients with low SES have more cardiovascular and non-cardiovascular comorbidities than their high SES counterparts with low SES patients receiving less coronary angiography and PCI associated with higher inhospital mortality, MACCE, and ischemic stroke, especially in the STEMI patients. Over a 11-year study period significant differences in terms of management and in-hospital 
clinical outcomes were observed which were largely mitigated towards the end of the study period (2013-2014). Our findings underscore the importance of a continued multilevel, collaborative approach with easy access to healthcare particularly in low SES zip codes. 


\section{References:}

1. Winkleby MA, Kraemer HC, Ahn DK, Varady AN. Ethnic and socioeconomic differences in cardiovascular disease risk factors: findings for women from the Third National Health and Nutrition Examination Survey, 1988-1994. JAMA 1998;280:356-362.

2. Franks P, Winters PC, Tancredi DJ, Fiscella KA. Do changes in traditional coronary heart disease risk factors over time explain the association between socio-economic status and coronary heart disease? BMC Cardiovasc Disord 2011;11:28.

3. Stringhini S, Carmeli C, Jokela M, Avendano M, Muennig P, Guida F, Ricceri F, d'Errico A, Barros H, Bochud M, Chadeau-Hyam M, Clavel-Chapelon F, Costa G, Delpierre C, Fraga S, Goldberg M, Giles GG, Krogh V, Kelly-Irving M, Layte R, Lasserre AM, Marmot MG, Preisig M, Shipley MJ, Vollenweider P, Zins M, Kawachi I, Steptoe A, Mackenbach JP, Vineis P, Kivimaki M, consortium L. Socioeconomic status and the 25 x 25 risk factors as determinants of premature mortality: a multicohort study and meta-analysis of 1.7 million men and women. Lancet 2017;389:1229-1237.

4. Daly MC, Duncan GJ, McDonough P, Williams DR. Optimal indicators of socioeconomic status for health research. Am J Public Health 2002;92:1151-1157.

5. Schultz WM, Kelli HM, Lisko JC, Varghese T, Shen J, Sandesara P, Quyyumi AA, Taylor HA, Gulati M, Harold JG, Mieres JH, Ferdinand KC, Mensah GA, Sperling LS. Socioeconomic Status and Cardiovascular Outcomes: Challenges and Interventions. Circulation 2018;137:2166-2178.

6. Biswas S, Andrianopoulos N, Duffy SJ, Lefkovits J, Brennan A, Walton A, Chan W, Noaman S, Shaw JA, Ajani A, Clark DJ, Freeman M, Hiew C, Oqueli E, Reid CM, Stub D. Impact of Socioeconomic Status on Clinical Outcomes in Patients With ST-SegmentElevation Myocardial Infarction. Circ Cardiovasc Qual Outcomes 2019;12:e004979. 
7. Agarwal S, Garg A, Parashar A, Jaber WA, Menon V. Outcomes and resource utilization in ST-elevation myocardial infarction in the United States: evidence for socioeconomic disparities. J Am Heart Assoc 2014;3:e001057.

8. Rao SV, Schulman KA, Curtis LH, Gersh BJ, Jollis JG. Socioeconomic status and outcome following acute myocardial infarction in elderly patients. Arch Intern Med 2004;164:1128-1133.

9. Abbasi SH, De Leon AP, Kassaian SE, Karimi A, Sundin O, Jalali A, Soares J, Macassa G. Socioeconomic Status and in-hospital Mortality of Acute Coronary Syndrome: Can Education and Occupation Serve as Preventive Measures? Int J Prev Med 2015;6:36.

10. HCUP National Inpatient Sample (NIS) Healthcare Cost and Utilization Project (HCUP), Agency for Healthcare Research and Quality, Rockville, MD, 2012.

11. Potts J, Kwok CS, Ensor J, Rashid M, Kadam U, Kinnaird T, Curzen N, Pancholy SB, Van der Windt D, Riley RD, Bagur R, Mamas MA. Temporal Changes in Co-Morbidity Burden in Patients Having Percutaneous Coronary Intervention and Impact on Prognosis. Am J Cardiol 2018;122:712-722.

12. Jakobsen L, Niemann T, Thorsgaard N, Thuesen L, Lassen JF, Jensen LO, Thayssen P, Ravkilde J, Tilsted HH, Mehnert F, Johnsen SP. Dimensions of socioeconomic status and clinical outcome after primary percutaneous coronary intervention. Circ Cardiovasc Interv 2012;5:641-648.

13. Bonow RO, Grant AO, Jacobs AK. The cardiovascular state of the union: confronting healthcare disparities. Circulation 2005;111:1205-1207.

14. Mensah GA, Mokdad AH, Ford ES, Greenlund KJ, Croft JB. State of disparities in cardiovascular health in the United States. Circulation 2005;111:1233-1241. 
15. Mehran R, Rao SV, Bhatt DL, Gibson CM, Caixeta A, Eikelboom J, Kaul S, Wiviott SD, Menon V, Nikolsky E, Serebruany V, Valgimigli M, Vranckx P, Taggart D, Sabik JF, Cutlip DE, Krucoff MW, Ohman EM, Steg PG, White H. Standardized bleeding definitions for cardiovascular clinical trials: a consensus report from the Bleeding Academic Research Consortium. Circulation 2011;123:2736-2747.

16. Yong CM, Abnousi F, Asch SM, Heidenreich PA. Socioeconomic inequalities in quality of care and outcomes among patients with acute coronary syndrome in the modern era of drug eluting stents. J Am Heart Assoc 2014;3:e01029.

17. Alter DA, Chong A, Austin PC, Mustard C, Iron K, Williams JI, Morgan CD, Tu JV, Irvine J, Naylor CD, Group SS. Socioeconomic status and mortality after acute myocardial infarction. Ann Intern Med 2006;144:82-93.

18. Bergstrom G, Redfors B, Angeras O, Dworeck C, Shao Y, Haraldsson I, Petursson P, Milicic D, Wedel H, Albertsson P, Ramunddal T, Rosengren A, Omerovic E. Low socioeconomic status of a patient's residential area is associated with worse prognosis after acute myocardial infarction in Sweden. Int J Cardiol 2015;182:141-147.

19. World Health Organization. Global action plan for the prevention and control of NCDs 2013-2020: World Health Organization, 2012.

20. World Health Organization and the United Nations Children's Fund (UNICEF). A vision for primary health care in the 21 st century: towards universal health coverage and the Sustainable Development Goals 2018;(WHO/HIS/SDS/2018.X).

21. Services USDoHaH. Healthy People 2030 Framework, 2020.

22. Berkowitz SA, Traore CY, Singer DE, Atlas SJ. Evaluating area-based socioeconomic status indicators for monitoring disparities within health care systems: results from a primary care network. Health Serv Res 2015;50:398-417. 
23. Thomas AJ, Eberly LE, Davey Smith G, Neaton JD, Multiple Risk Factor Intervention Trial Research G. ZIP-code-based versus tract-based income measures as long-term riskadjusted mortality predictors. Am J Epidemiol 2006;164:586-590. 
Figure titles and legends:

Figure 1. Receipt of CA and PCI according to the MHI: A. In total cohort; B. In AMI subtypes.

Legend: AMI - Acute Myocardial Infarction; CA - Coronary Angiography; MHI - Median Household Income; NSTEMI - non-ST-elevation Myocardial Infarction; PCI - Percutaneous Coronary Intervention; STEMI - ST-elevation Myocardial Infarction.

Figure 2. The trend of adjusted odds for invasive management according to the MHI from 2004 to 2014.

Legend: *Reference group: 0th-25th $(\mathrm{n}=1884699)$ group; $p<0.001$ for all trends.

CA - Coronary Angiography; MHI - Median Household Income; PCI - Percutaneous Coronary

Intervention.

Figure 3. The trend of adjusted odds for different clinical outcomes according to the MHI from 2004 to 2014.

Legend: *Reference group: 0th-25th $(\mathrm{n}=1884699)$ group; $p<0.001$ for all trends.

MACCE - Major Adverse Cardiovascular and Cerebrovascular Events; MHI - Median Household Income. 
Table 1. Patient characteristics according to Median Household Income (percentile)

$$
\text { Variables } \quad 0^{\text {th }}-25^{\text {th }}(n=1884699) \quad 26^{\text {th }}-50^{\text {th }}(n=1806775)
$$

$51^{\text {st }}-75^{\text {th }}(n=1567720) \quad 76^{\text {th }}-100^{\text {th }}(n=1344515) \quad p$-value

Age at admission (years),

median (IQR)

$67(56,78) \quad 68(57,79) \quad 68(57,79) \quad 69(57,80) \quad<0.001$

\begin{tabular}{|c|c|c|c|c|c|}
\hline Women & $42.0 \%$ & $40.1 \%$ & $38.8 \%$ & $37.4 \%$ & $<0.001$ \\
\hline STEMI & $34.2 \%$ & $35.4 \%$ & $35.5 \%$ & $35.4 \%$ & $<0.001$ \\
\hline
\end{tabular}

\section{Charlson comorbidity index}

(CCI) score

$<0.001$

\begin{tabular}{lcccc}
\hline $\mathbf{0}$ & $37.8 \%$ & $40.5 \%$ & $42.4 \%$ & $45.9 \%$ \\
\hline $\mathbf{1}$ & $38.4 \%$ & $37.3 \%$ & $36.3 \%$ & $34.9 \%$ \\
\hline $\mathbf{2}$ & $16.8 \%$ & $15.7 \%$ & $15.0 \%$ & $13.5 \%$ \\
\hline$\geq 3$ & $7.0 \%$ & $6.5 \%$ & $6.3 \%$ & $5.7 \%$ \\
\hline Dyslipidaemia & $51.5 \%$ & $54.1 \%$ & $56.8 \%$ & $<0.001$ \\
\hline Smoker & $35.5 \%$ & $35.2 \%$ & $33.9 \%$ & $<0.4 \%$ \\
\hline Previous AMI & $10.1 \%$ & $10.1 \%$ & $10.3 \%$ & $<0.001$ \\
\hline
\end{tabular}




\begin{tabular}{|c|c|c|c|c|c|}
\hline Previous PCl & $11.3 \%$ & $11.4 \%$ & $11.4 \%$ & $11.5 \%$ & 0.001 \\
\hline Previous CABG & $7.6 \%$ & $7.6 \%$ & $7.4 \%$ & $7.4 \%$ & $<0.001$ \\
\hline Previous CVA & $4.0 \%$ & $3.7 \%$ & $3.7 \%$ & $3.5 \%$ & $<0.001$ \\
\hline Atrial fibrillation & $15.3 \%$ & $16.4 \%$ & $17.0 \%$ & $17.9 \%$ & $<0.001$ \\
\hline History of IHD & $75.5 \%$ & $76.9 \%$ & $77.7 \%$ & $77.0 \%$ & $<0.001$ \\
\hline Family history of CAD & $7.2 \%$ & $7.6 \%$ & $8.1 \%$ & $8.5 \%$ & $<0.001$ \\
\hline Deficiency anemias & $15.2 \%$ & $14.1 \%$ & $14.5 \%$ & $14.4 \%$ & $<0.001$ \\
\hline Chronic blood loss anemia & $1.1 \%$ & $1.1 \%$ & $1.1 \%$ & $1.1 \%$ & 0.018 \\
\hline Congestive heart failure & $1.0 \%$ & $0.9 \%$ & $0.8 \%$ & $0.8 \%$ & $<0.001$ \\
\hline Valvular disease & $0.2 \%$ & $0.3 \%$ & $0.2 \%$ & $0.3 \%$ & $<0.001$ \\
\hline Hypertension & $67.7 \%$ & $66.0 \%$ & $65.9 \%$ & $65.2 \%$ & $<0.001$ \\
\hline Cardiogenic shock & $4.7 \%$ & $4.8 \%$ & $5.0 \%$ & $5.1 \%$ & $<0.001$ \\
\hline Peripheral vascular disorders & $11.0 \%$ & $11.1 \%$ & $10.8 \%$ & $10.1 \%$ & $<0.001$ \\
\hline \multicolumn{6}{|l|}{ Pulmonary circulation } \\
\hline disorders & $0.1 \%$ & $0.1 \%$ & $0.1 \%$ & $0.1 \%$ & 0.001 \\
\hline
\end{tabular}









\begin{tabular}{|c|c|c|c|c|c|}
\hline Renal failure & $17.5 \%$ & $16.3 \%$ & $16.0 \%$ & $15.6 \%$ & $<0.001$ \\
\hline Other neurological disorders & $6.0 \%$ & $5.7 \%$ & $5.6 \%$ & $5.7 \%$ & $<0.001$ \\
\hline Paralysis & $1.8 \%$ & $1.5 \%$ & $1.6 \%$ & $1.5 \%$ & $<0.001$ \\
\hline Psychoses & $2.3 \%$ & $2.0 \%$ & $1.9 \%$ & $1.7 \%$ & $<0.001$ \\
\hline $\begin{array}{l}\text { Rheumatoid arthritis/collagen } \\
\text { vascular diseases }\end{array}$ & $2.0 \%$ & $2.1 \%$ & $2.2 \%$ & $2.3 \%$ & $<0.001$ \\
\hline $\begin{array}{l}\text { Solid tumor without } \\
\text { metastasis }\end{array}$ & $1.4 \%$ & $1.4 \%$ & $1.4 \%$ & $1.5 \%$ & $<0.001$ \\
\hline Metastatic cancer & $0.8 \%$ & $0.8 \%$ & $0.9 \%$ & $1.0 \%$ & $<0.001$ \\
\hline Lymphoma & $0.4 \%$ & $0.5 \%$ & $0.5 \%$ & $0.6 \%$ & $<0.001$ \\
\hline Fluid and electrolyte disorders & $19.7 \%$ & $18.8 \%$ & $19.0 \%$ & $18.5 \%$ & $<0.001$ \\
\hline Weekend admission & $26.1 \%$ & $26.0 \%$ & $25.9 \%$ & $25.6 \%$ & $<0.001$ \\
\hline Admission type (Elective vs. No & & & & & $<0.001$ \\
\hline Elective & $8.1 \%$ & $7.5 \%$ & $6.3 \%$ & $6.1 \%$ & \\
\hline Non-elective & $91.9 \%$ & $92.5 \%$ & $93.7 \%$ & $93.9 \%$ & \\
\hline
\end{tabular}


Primary expected payer

$<0.001$

\begin{tabular}{|c|c|c|c|c|c|}
\hline Medicare & $59.1 \%$ & $58.3 \%$ & $56.2 \%$ & $55.3 \%$ & \\
\hline Medicaid & $8.7 \%$ & $5.9 \%$ & $4.7 \%$ & $3.2 \%$ & \\
\hline Private Insurance & $21.0 \%$ & $26.4 \%$ & $30.7 \%$ & $35.4 \%$ & \\
\hline Self-pay & $7.5 \%$ & $6.0 \%$ & $5.2 \%$ & $3.6 \%$ & \\
\hline No charge & $0.7 \%$ & $0.6 \%$ & $0.6 \%$ & $0.3 \%$ & \\
\hline Other & $3.0 \%$ & $2.8 \%$ & $2.6 \%$ & $2.1 \%$ & \\
\hline Bed size of hospital & & & & & $<0.001$ \\
\hline Small & $8.8 \%$ & $11.0 \%$ & $11.2 \%$ & $11.0 \%$ & \\
\hline Medium & $23.4 \%$ & $23.3 \%$ & $24.6 \%$ & $26.6 \%$ & \\
\hline Large & $67.9 \%$ & $65.7 \%$ & $64.1 \%$ & $62.4 \%$ & \\
\hline Hospital Region & & & & & $<0.001$ \\
\hline Northeast & $12.4 \%$ & $15.8 \%$ & $20.7 \%$ & $32.9 \%$ & \\
\hline Midwest & $19.2 \%$ & $29.1 \%$ & $26.2 \%$ & $18.2 \%$ & \\
\hline South & $57.1 \%$ & $40.0 \%$ & $32.1 \%$ & $24.7 \%$ & \\
\hline
\end{tabular}




\begin{tabular}{|c|c|c|c|c|c|}
\hline West & $11.3 \%$ & $15.1 \%$ & $21.1 \%$ & $24.2 \%$ & \\
\hline \multicolumn{3}{|c|}{ Location/teaching status of hospital } & & & $<0.001$ \\
\hline Rural & $19.4 \%$ & $13.5 \%$ & $4.4 \%$ & $1.1 \%$ & \\
\hline Urban non-teaching & $34.2 \%$ & $42.6 \%$ & $46.7 \%$ & $46.0 \%$ & \\
\hline Urban teaching & $46.4 \%$ & $43.9 \%$ & $48.9 \%$ & $52.9 \%$ & \\
\hline
\end{tabular}

Notes: Dyslipidemia indicates disorders of lipid metabolism and was defined by code 53 of the Clinical Classification Software.

Abbreviations: AIDS - Acquired Immunodeficiency Syndrome; AMI - Acute Myocardial Infarction; CABG - Coronary Artery Bypass Graft; CAD - Coronary Artery Disease; CVA - Cerebrovascular Accidents; IHD - Ischemic Heart Disease; IQR - Interquartile Range; PCI - Percutaneous Coronary Intervention; SD - Standard Deviation; STEMI - STelevation Myocardial Infarction. 
Table 2. Comparison of clinical outcomes and invasive management between the different Median Household Income groups Variables $\quad 0^{\text {th }}-25^{\text {th }}(n=1884699) \quad 26^{\text {th }}-50^{\text {th }}(n=1806775) \quad 51^{\text {st }}-75^{\text {th }}(n=1567720) \quad 7^{\text {th }}-100^{\text {th }}(n=1344515) \quad p$-value

\section{Receipt of CA}

\begin{tabular}{|c|c|c|c|c|c|}
\hline Total cohort & $63.4 \%$ & $64.6 \%$ & $65.7 \%$ & $64.3 \%$ & $<0.001$ \\
\hline NSTEMI & $59.7 \%$ & $60.1 \%$ & $60.1 \%$ & $57.8 \%$ & $<0.001$ \\
\hline STEMI & $70.5 \%$ & $72.7 \%$ & $76.0 \%$ & $76.3 \%$ & $<0.001$ \\
\hline \multicolumn{6}{|l|}{ Receipt of PCl } \\
\hline Total cohort & $40.4 \%$ & $42.7 \%$ & $44.8 \%$ & $44.3 \%$ & $<0.001$ \\
\hline NSTEMI & $31.3 \%$ & $32.8 \%$ & $33.8 \%$ & $32.7 \%$ & $<0.001$ \\
\hline STEMI & $58.0 \%$ & $60.7 \%$ & $64.8 \%$ & $65.5 \%$ & $<0.001$ \\
\hline \multicolumn{6}{|l|}{ Receipt of CABG } \\
\hline Total cohort & $8.9 \%$ & $9.1 \%$ & $8.9 \%$ & $8.5 \%$ & $<0.001$ \\
\hline NSTEMI & $9.5 \%$ & $9.7 \%$ & $9.5 \%$ & $9.2 \%$ & $<0.001$ \\
\hline STEMI & $7.7 \%$ & $7.9 \%$ & $7.8 \%$ & $7.4 \%$ & $<0.001$ \\
\hline
\end{tabular}

\section{Receipt of thrombolysis}




\begin{tabular}{ccccc}
\hline Total cohort & $0.4 \%$ & $0.4 \%$ & $0.5 \%$ & $0.6 \%$ \\
NSTEMI & $0.2 \%$ & $0.2 \%$ & $0.2 \%$ & $0.3 \%$ \\
\hline STEMI & $0.8 \%$ & $0.8 \%$ & $0.9 \%$ & $<0.001$ \\
\hline
\end{tabular}

\section{Use of assist device or IABP}

\begin{tabular}{ccccc} 
Total cohort & $4.5 \%$ & $4.8 \%$ & $5.1 \%$ & $5.5 \%$ \\
\hline NSTEMI & $2.7 \%$ & $2.7 \%$ & $2.8 \%$ & $<.0 \%$ \\
\hline STEMI & $8.1 \%$ & $8.6 \%$ & $9.2 \%$ & $<0.001$ \\
\hline
\end{tabular}

\section{In-hospital MACCE}

\begin{tabular}{|c|c|c|c|c|c|}
\hline Total cohort & $8.1 \%$ & $7.8 \%$ & $7.7 \%$ & $7.7 \%$ & $<0.001$ \\
\hline NSTEMI & $6.3 \%$ & $6.2 \%$ & $6.2 \%$ & $6.3 \%$ & $<0.001$ \\
\hline STEMI & $11.4 \%$ & $10.9 \%$ & $10.5 \%$ & $10.3 \%$ & $<0.001$ \\
\hline \multicolumn{6}{|l|}{ In-hospital mortality } \\
\hline Total cohort & $6.0 \%$ & $5.9 \%$ & $5.7 \%$ & $5.7 \%$ & $<0.001$ \\
\hline NSTEMI & $4.3 \%$ & $4.2 \%$ & $4.1 \%$ & $4.2 \%$ & $<0.001$ \\
\hline STEMI & $9.4 \%$ & $9.0 \%$ & $8.5 \%$ & $8.3 \%$ & $<0.001$ \\
\hline
\end{tabular}


In-hospital all-cause bleeding

\begin{tabular}{|c|c|c|c|c|c|}
\hline Total cohort & $5.0 \%$ & $5.2 \%$ & $5.5 \%$ & $5.7 \%$ & $<0.001$ \\
\hline NSTEMI & $5.2 \%$ & $5.4 \%$ & $5.6 \%$ & $5.6 \%$ & $<0.001$ \\
\hline STEMI & $4.7 \%$ & $4.9 \%$ & $5.5 \%$ & $5.7 \%$ & $<0.001$ \\
\hline
\end{tabular}

\section{In-hospital ischemic stroke}

\begin{tabular}{|c|c|c|c|c|c|}
\hline Total cohort & $1.8 \%$ & $1.7 \%$ & $1.7 \%$ & $1.7 \%$ & $<0.001$ \\
\hline NSTEMI & $1.9 \%$ & $1.8 \%$ & $1.8 \%$ & $1.8 \%$ & $<0.001$ \\
\hline STEMI & $1.7 \%$ & $1.5 \%$ & $1.5 \%$ & $1.4 \%$ & $<0.001$ \\
\hline
\end{tabular}

\section{In-hospital cardiac}

complications

\begin{tabular}{|c|c|c|c|c|c|}
\hline Total cohort & $0.6 \%$ & $0.7 \%$ & $0.7 \%$ & $0.7 \%$ & $<0.001$ \\
\hline NSTEMI & $0.4 \%$ & $0.5 \%$ & $0.5 \%$ & $0.5 \%$ & $<0.001$ \\
\hline STEMI & $0.9 \%$ & $1.0 \%$ & $1.1 \%$ & $1.1 \%$ & $<0.001$ \\
\hline
\end{tabular}

\section{Length of stay (days)}

Total cohort

$3(2,6)$

$3(2,6)$

$3(2,6)$

$3(2,6)$

$<0.001$

$3(2,6)$




\begin{tabular}{ccccc} 
NSTEMI & $4(2,7)$ & $4(2,6)$ & $3(2,6)$ & $3(2,6)$ \\
STEMI & $3(2,6)$ & $3(2,5)$ & $3(2,5)$ & $3(2,5)$ \\
\hline
\end{tabular}

Total charges, US Dollars

\begin{tabular}{cccccc}
\hline Total cohort & $40939(20912,71953)$ & $41208(21118,71665)$ & $44639(23940,77011)$ & $47676(25146,82276)$ & $<0.001$ \\
\hline NSTEMI & $34732(18047,62686)$ & $34362(17743,62163)$ & $37417(19740,67221)$ & $39895(20494,71637)$ & $<0.001$ \\
\hline STEMI & $41298(20812,68627)$ & $42798(23486,69763)$ & $47265(28323,76956)$ & $51545(30615,83956)$ & $<0.001$
\end{tabular}

Abbreviations: CA - Coronary Angiography; CABG - Coronary Artery Bypass Graft; IABP - Intra-aortic Balloon Pump; MACCE - Major Adverse Cardiac and Cerebrovascular Events (composite of mortality, acute stroke/ transient ischemic attack and cardiac complications); $\mathrm{PCl}$ - Percutaneous Coronary Intervention. 
Table 3. Adjusted odds of in-hospital treatments and outcomes according to the Median Household Income group in total cohort*.

\begin{tabular}{l|c|c|c|c|c|c}
\hline \multicolumn{1}{c|}{ Outcome } & $26^{\text {th }}-50^{\text {th }}(\mathrm{n}=1806775)$ & \multicolumn{2}{|c|}{${51^{\text {st }}-75^{\text {th }}(\mathrm{n}=1567720)}^{7^{\text {th }}-100^{\text {th }}(\mathrm{n}=1344515)}$} \\
\hline & OR $[95 \% \mathrm{Cl}]$ & $p$-value & OR $[95 \% \mathrm{Cl}]$ & $p$-value & OR $[95 \% \mathrm{Cl}]$ & $p$-value \\
\hline Treatments: & & & & \\
\hline
\end{tabular}

\begin{tabular}{ccccccc}
\hline Receipt of CA & $1.06[1.06,1.07]$ & $<0.001$ & $1.02[1.02,1.03]$ & $<0.001$ & $0.95[0.95,0.96]$ & $<0.001$ \\
\hline Receipt of PCI & $1.09[1.09,1.10]$ & $<0.001$ & $1.14[1.13,1.14]$ & $<0.001$ & $1.10[1.10,1.11]$ \\
\hline Outcomes: & & & & $<0.001$ \\
MACCE & $0.98[0.97,0.99]$ & $<0.001$ & $0.95[0.95,0.96]$ & $<0.001$ & $0.91[0.91,0.92]$ \\
\hline Mortality & $0.97[0.96,0.98]$ & $<0.001$ & $0.94[0.93,0.95]$ & $<0.001$ & $0.88[0.88,0.89]$ \\
\hline Acute stroke/TIA & $0.95[0.93,0.96]$ & $<0.001$ & $0.93[0.92,0.95]$ & $<0.001$ & $0.90[0.88,0.91]$ \\
\hline All-cause bleeding & $1.04[1.03,1.05]$ & $<0.001$ & $1.06[1.05,1.07]$ & $<0.001$ & $<0.001$ \\
\hline
\end{tabular}

*Reference group: $0^{\text {th }}-25^{\text {th }}(\mathrm{n}=1884699)$ group

Abbreviations: CA - Coronary Angiography; Cl - Confidence Interval; MACCE - Major Adverse Cardiac and Cerebrovascular Events (composite of mortality, acute stroke/transient ischemic attack and cardiac complications); OR - Odds Ratios; PCI - Percutaneous Coronary Intervention; TIA - transitory ischemic attack. 

Table 4. Adjusted odds of in-hospital outcomes according to the Median Household Income group in AMI subgroups*.

\begin{tabular}{l|c|c|c|c|c|c}
\hline \multicolumn{1}{c|}{ Outcome } & $26^{\text {th }}-50^{\text {th }}(\mathrm{n}=1806775)$ & $51^{\text {st }}-75^{\text {th }}(\mathrm{n}=1567720)$ & $7^{\text {th }}-100^{\text {th }}(\mathrm{n}=1344515)$ \\
\hline & OR $[95 \% \mathrm{Cl}]$ & $p$-value & OR $[95 \% \mathrm{Cl}]$ & $p$-value & OR $[95 \% \mathrm{Cl}]$ & $p$-value \\
\hline Treatments: & & & & \\
\hline
\end{tabular}

\section{Treatments:}

\section{Receipt of CA}

\begin{tabular}{ccccccc} 
NSTEMI & $1.05[1.05,1.06]$ & $<0.001$ & $0.99[0.98,0.99]$ & $<0.001$ & $0.91[0.90,0.91]$ & $<0.001$ \\
\hline STEMI & $1.06[1.05,1.07]$ & $<0.001$ & $1.08[1.07,1.09]$ & $<0.001$ & $1.04[1.03,1.05]$ & $<0.001$
\end{tabular}

\section{Receipt of PCI}

\begin{tabular}{|c|c|c|c|c|c|c|}
\hline NSTEMI & $1.08[1.07,1.09]$ & $<0.001$ & $1.09[1.08,1.10]$ & $<0.001$ & $1.04[1.03,1.05]$ & $<0.001$ \\
\hline STEMI & $1.08[1.07,1.09]$ & $<0.001$ & $1.17[1.16,1.18]$ & $<0.001$ & $1.17[1.16,1.18]$ & $<0.001$ \\
\hline
\end{tabular}

\section{Outcomes:}

\section{MACCE}

\begin{tabular}{|c|c|c|c|c|c|c|}
\hline NSTEMI & $0.98[0.97,0.99]$ & $<0.001$ & $0.96[0.95,0.97]$ & $<0.001$ & $0.93[0.92,0.94]$ & $<0.001$ \\
\hline STEMI & $0.98[0.96,0.99]$ & $<0.001$ & $0.95[0.94,0.97]$ & $<0.001$ & $0.90[0.89,0.91]$ & $<0.001$ \\
\hline
\end{tabular}

\section{Mortality}




\begin{tabular}{ccccccc} 
NSTEMI & $0.97[0.96,0.98]$ & $<0.001$ & $0.94[0.92,0.95]$ & $<0.001$ & $0.90[0.88,0.91]$ & $<0.001$ \\
\hline STEMI & $0.97[0.95,0.98]$ & $<0.001$ & $0.94[0.93,0.96]$ & $<0.001$ & $0.88[0.87,0.89]$
\end{tabular}

\begin{tabular}{|c|c|c|c|c|c|c|}
\hline \multicolumn{7}{|c|}{ Acute stroke/TIA } \\
\hline NSTEMI & $0.95[0.93,0.97]$ & $<0.001$ & $0.93[0.91,0.95]$ & $<0.001$ & $0.90[0.88,0.92]$ & $<0.001$ \\
\hline STEMI & $0.95[0.92,0.98]$ & 0.001 & $0.96[0.93,0.99]$ & 0.006 & $0.90[0.87,0.93]$ & $<0.001$ \\
\hline
\end{tabular}

\section{All-cause bleeding}

\begin{tabular}{|c|c|c|c|c|c|c|}
\hline NSTEMI & $1.05[1.04,1.06]$ & $<0.001$ & $1.05[1.04,1.06]$ & $<0.001$ & $1.07[1.05,1.08]$ & $<0.001$ \\
\hline STEMI & $1.02[1.00,1.03]$ & 0.043 & $1.09[1.07,1.11]$ & $<0.001$ & $1.11[1.09,1.13]$ & $<0.001$ \\
\hline
\end{tabular}

*Reference group: $0^{\text {th }}-25^{\text {th }}(\mathrm{n}=1884699)$ group.

Abbreviations: AMI - Acute Myocardial Infarction; CA - Coronary Angiography; Cl - Confidence Interval; MACCE - Major Adverse Cardiac and Cerebrovascular Events (composite of mortality, acute stroke/transient ischemic attack and cardiac complications); NSTEMI - non-ST-elevation Myocardial Infarction; OR - Odds Ratios; PCI Percutaneous Coronary Intervention; STEMI - ST-elevation Myocardial Infarction; TIA - Transitory Ischemic Attack. 
Table 5. Trend of in-hospital outcomes and invasive management from 2004 to 2014.

\begin{tabular}{|c|c|c|c|c|c|}
\hline Outcome/Year-- & 2004-2006 & 2007-2009 & 2010-2012 & 2013-2014 & $p$-value (for trend) \\
\hline \multicolumn{6}{|l|}{ MACCE } \\
\hline $0^{\text {th }}-25^{\text {th }} \mathrm{MHI}$ & $9.0 \%$ & $8.2 \%$ & $7.5 \%$ & $7.1 \%$ & $<0.001$ \\
\hline $26^{\text {th }}-50^{\text {th }} \mathrm{MHI}$ & $8.6 \%$ & $8.2 \%$ & $7.2 \%$ & $7.1 \%$ & $<0.001$ \\
\hline $51^{\text {st }}-75^{\text {th }} \mathrm{MHI}$ & $8.4 \%$ & $8.1 \%$ & $7.1 \%$ & $7.0 \%$ & $<0.001$ \\
\hline $76^{\text {th }}-100^{\text {th }} \mathrm{MHI}$ & $8.3 \%$ & $7.8 \%$ & $7.2 \%$ & $7.1 \%$ & $<0.001$ \\
\hline \multicolumn{6}{|l|}{ Mortality } \\
\hline $0^{\text {th }}-25^{\text {th }} \mathrm{MHI}$ & $7.1 \%$ & $6.1 \%$ & $5.5 \%$ & $5.1 \%$ & $<0.001$ \\
\hline $26^{\text {th }}-50^{\text {th }} \mathrm{MHI}$ & $6.8 \%$ & $6.0 \%$ & $5.2 \%$ & $4.9 \%$ & $<0.001$ \\
\hline $51^{\text {st }}-75^{\text {th }} \mathrm{MHI}$ & $6.5 \%$ & $5.9 \%$ & $5.1 \%$ & $4.8 \%$ & $<0.001$ \\
\hline $76^{\text {th }}-100^{\text {th }} \mathrm{MHI}$ & $6.5 \%$ & $5.6 \%$ & $5.2 \%$ & $5.0 \%$ & $<0.001$ \\
\hline \multicolumn{6}{|l|}{ Acute stroke/TIA } \\
\hline $0^{\text {th }}-25^{\text {th }} \mathrm{MHI}$ & $2.0 \%$ & $1.9 \%$ & $1.7 \%$ & $1.6 \%$ & $<0.001$ \\
\hline $26^{\text {th }}-50^{\text {th }} \mathrm{MHI}$ & $1.7 \%$ & $1.8 \%$ & $1.5 \%$ & $1.7 \%$ & $<0.001$ \\
\hline
\end{tabular}




\begin{tabular}{|c|c|c|c|c|c|}
\hline $51^{\text {st }}-75^{\text {th }} \mathrm{MHI}$ & $1.8 \%$ & $1.8 \%$ & $1.5 \%$ & $1.6 \%$ & $<0.001$ \\
\hline $76^{\text {th }}-100^{\text {th }} \mathrm{MHI}$ & $1.7 \%$ & $1.7 \%$ & $1.6 \%$ & $1.6 \%$ & $<0.001$ \\
\hline \multicolumn{6}{|c|}{ Cardiac Complications } \\
\hline $0^{\text {th }}-25^{\text {th }} \mathrm{MHI}$ & $0.4 \%$ & $0.7 \%$ & $0.7 \%$ & $0.7 \%$ & $<0.001$ \\
\hline $26^{\text {th }}-50^{\text {th }} \mathrm{MHI}$ & $0.5 \%$ & $0.7 \%$ & $0.8 \%$ & $0.8 \%$ & $<0.001$ \\
\hline $51^{\text {st }}-75^{\text {th }} \mathrm{MHI}$ & $0.5 \%$ & $0.8 \%$ & $0.8 \%$ & $0.9 \%$ & $<0.001$ \\
\hline $76^{\text {th }}-100^{\text {th }} \mathrm{MHI}$ & $0.5 \%$ & $0.8 \%$ & $0.8 \%$ & $0.9 \%$ & $<0.001$ \\
\hline \multicolumn{6}{|c|}{ All-cause bleeding } \\
\hline $0^{\text {th }}-25^{\text {th }} \mathrm{MHI}$ & $3.9 \%$ & $4.8 \%$ & $5.7 \%$ & $6.1 \%$ & $<0.001$ \\
\hline $26^{\text {th }}-50^{\text {th }} \mathrm{MHI}$ & $4.1 \%$ & $5.0 \%$ & $5.9 \%$ & $6.4 \%$ & $<0.001$ \\
\hline $51^{\text {st }}-75^{\text {th }} \mathrm{MHI}$ & $4.6 \%$ & $5.4 \%$ & $6.0 \%$ & $6.7 \%$ & $<0.001$ \\
\hline $76^{\text {th }}-100^{\text {th }} \mathrm{MHI}$ & $5.1 \%$ & $5.7 \%$ & $5.8 \%$ & $6.5 \%$ & $<0.001$ \\
\hline \multicolumn{6}{|l|}{ CA } \\
\hline $0^{\text {th }}-25^{\text {th }} \mathrm{MHI}$ & $56.5 \%$ & $62.2 \%$ & $66.8 \%$ & $70.7 \%$ & $<0.001$ \\
\hline $26^{\text {th }}-50^{\text {th }} \mathrm{MHI}$ & $59.2 \%$ & $64.0 \%$ & $67.2 \%$ & $70.5 \%$ & $<0.001$ \\
\hline
\end{tabular}




\begin{tabular}{|c|c|c|c|c|c|}
\hline $51^{\text {st }}-75^{\text {th }} \mathrm{MHI}$ & $61.4 \%$ & $64.8 \%$ & $68.2 \%$ & $70.7 \%$ & $<0.001$ \\
\hline $76^{\text {th }}-100^{\text {th }} \mathrm{MHI}$ & $61.1 \%$ & $63.2 \%$ & $66.5 \%$ & $69.0 \%$ & $<0.001$ \\
\hline \multicolumn{6}{|l|}{$\mathrm{PCl}$} \\
\hline $0^{\text {th }}-25^{\text {th }} \mathrm{MHI}$ & $34.6 \%$ & $39.6 \%$ & $43.3 \%$ & $46.2 \%$ & $<0.001$ \\
\hline $26^{\text {th }}-50^{\text {th }} \mathrm{MHI}$ & $37.8 \%$ & $42.1 \%$ & $45.3 \%$ & $47.9 \%$ & $<0.001$ \\
\hline $51^{\text {st }}-75^{\text {th }} \mathrm{MHI}$ & $40.9 \%$ & $44.2 \%$ & $47.0 \%$ & $49.1 \%$ & $<0.001$ \\
\hline $76^{\text {th }}-100^{\text {th }} \mathrm{MHI}$ & $41.0 \%$ & $43.7 \%$ & $46.4 \%$ & $48.4 \%$ & $<0.001$ \\
\hline
\end{tabular}

Abbreviations: CA - Coronary Angiography; MACCE - Major Adverse Cardiac and Cerebrovascular Events (composite of mortality, acute stroke/transient and cardiac complications); $\mathrm{MHI}$ - Median Household Income; PCl - Percutaneous Coronary Intervention; TIA - Transitory Ischemic Attack. 




B

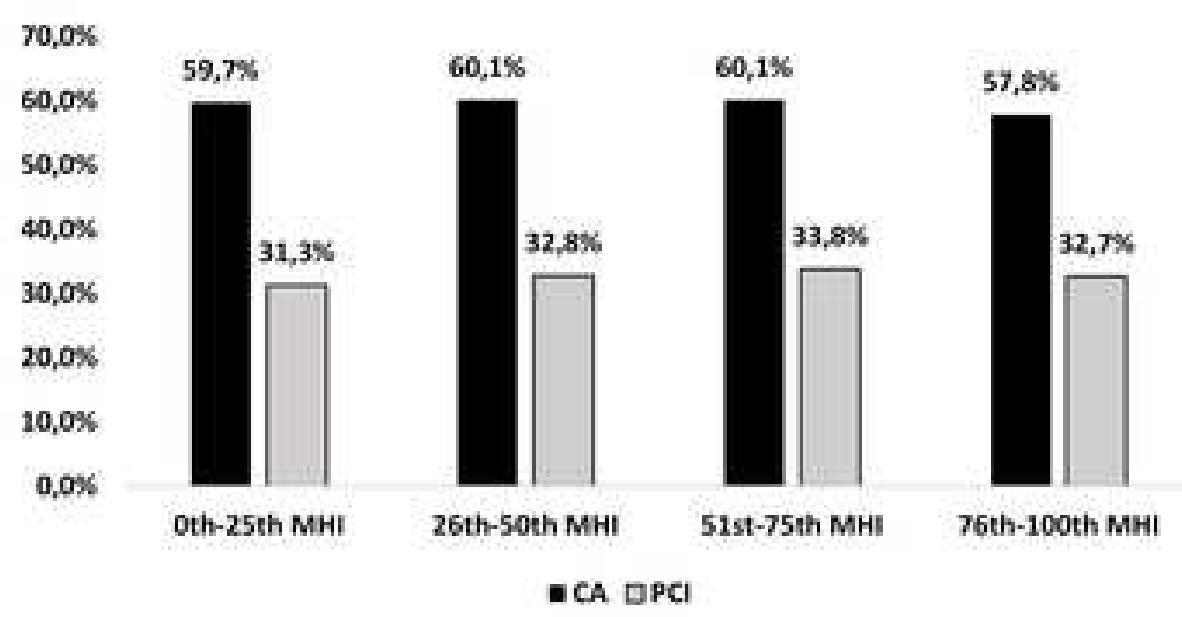

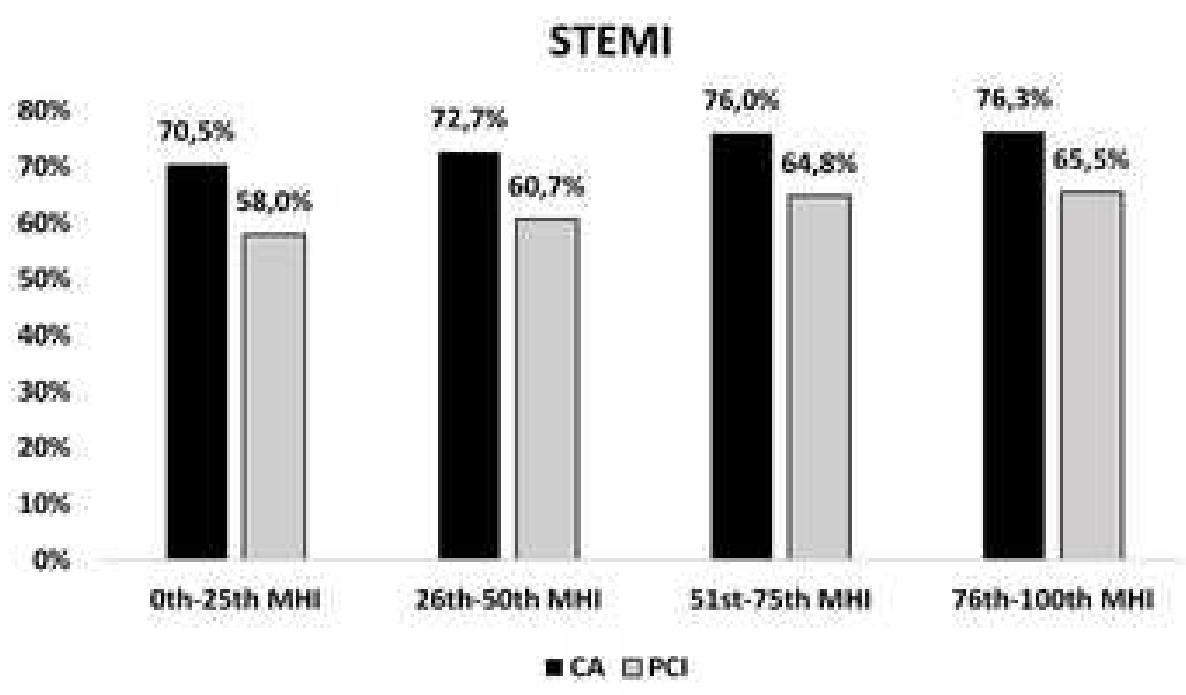


CA

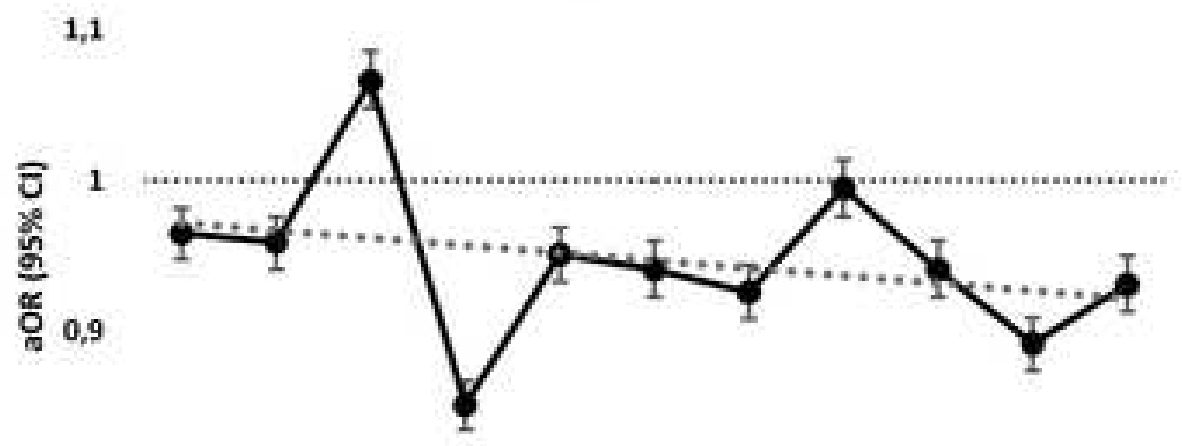

0.8

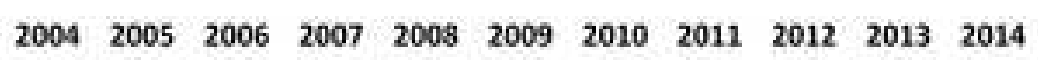

PCI

\section{1,3}

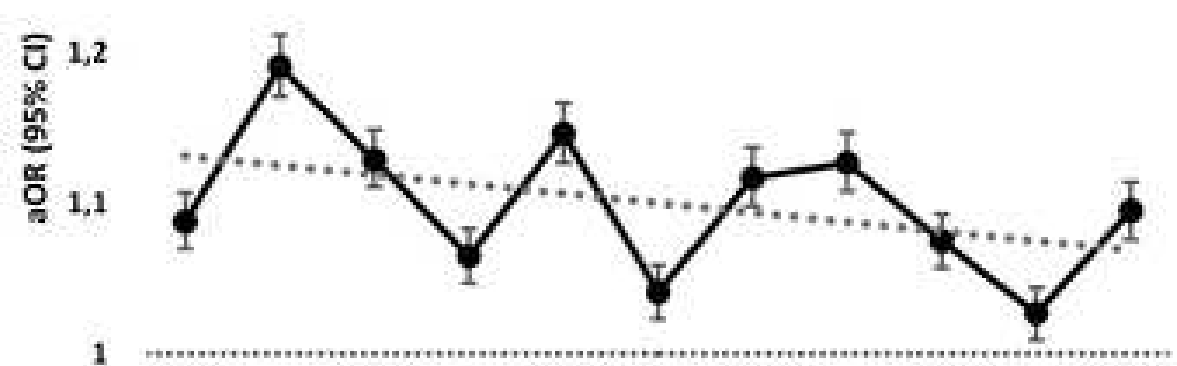

$\begin{array}{lllllllllll}2004 & 2005 & 2006 & 2007 & 2008 & 2009 & 2010 & 2011 & 2012 & 2013 & 2014\end{array}$

- 76th-100th MHI 


\section{MACCE}

1

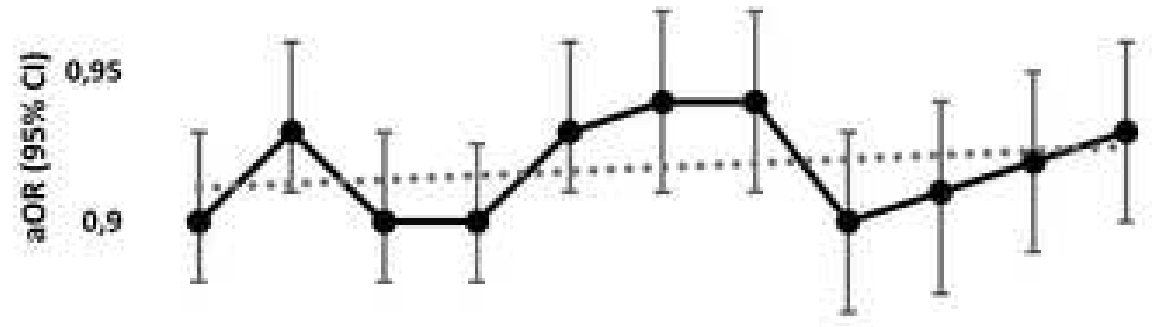

0,85

$\begin{array}{lllllllllll}2004 & 2005 & 2006 & 2007 & 2008 & 2009 & 2010 & 2011 & 2012 & 2013 & 2014\end{array}$

- 76th-100th MHI

\section{BLEEDING}

1,5



0,9



0.8

$\begin{array}{lllllllllll}2004 & 2005 & 2006 & 2007 & 2008 & 2009 & 2010 & 2011 & 2012 & 2013 & 2014\end{array}$

- 76th-100th MHI

\section{STROKE}

1,1

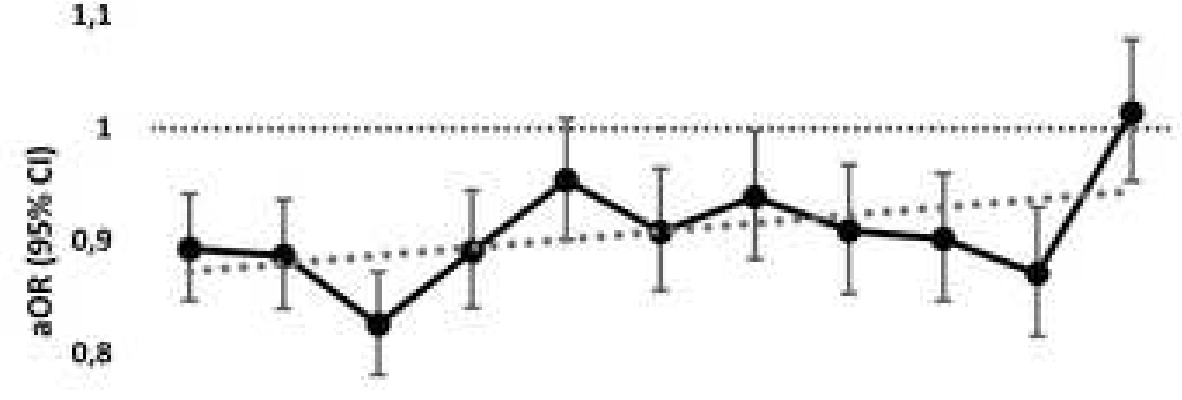

0,7

\footnotetext{
- 76th-100th MHI
} 
Click here to access/download Electronic Supplementary Material (online publication only)

Graphical Abstract.jpg 
Electronic Supplementary Material (online publication only)

Click here to access/download Electronic Supplementary Material (online publication only)

\section{MHI AMI Supplementary material_REVISED.docx}


Click here to access/download Electronic Supplementary Material (online publication only) Supplementary Figure S1.png 


\section{CRediT author statement}

Andrija Matetic: Software, Data curation, Methodology, Formal analysis, Visualization, Writing- Reviewing and Editing; Aditya Bharadwaj: Methodology, Writing- Original draft preparation, Writing- Reviewing and Editing, Validation; Mohamed Mohamed: Conceptualization, Methodology, Data curation, Formal analysis, Writing- Reviewing and Editing; Yashasvi Chugh: Validation, Writing- Reviewing and Editing; Sanjay Chugh: Validation, Writing- Reviewing and Editing; Margot Minissian: Validation, WritingReviewing and Editing; Amit Amin: Validation, Writing- Reviewing and Editing; Harriette Van Spall: Validation, Writing- Reviewing and Editing; David L. Fischman: Validation, Writing- Reviewing and Editing; Michael Savage: Validation, Writing- Reviewing and Editing; Annabelle Santos Volgman: Validation, Writing- Reviewing and Editing; Mamas A. Mamas: Supervision, Conceptualization, Methodology, Resources, Project administration, Validation, Writing- Reviewing and Editing. 


\section{Declaration of interests}

$\bigotimes$ The authors declare that they have no known competing financial interests or personal relationships that could have appeared to influence the work reported in this paper.

$\square$ The authors declare the following financial interests/personal relationships which may be considered as potential competing interests:

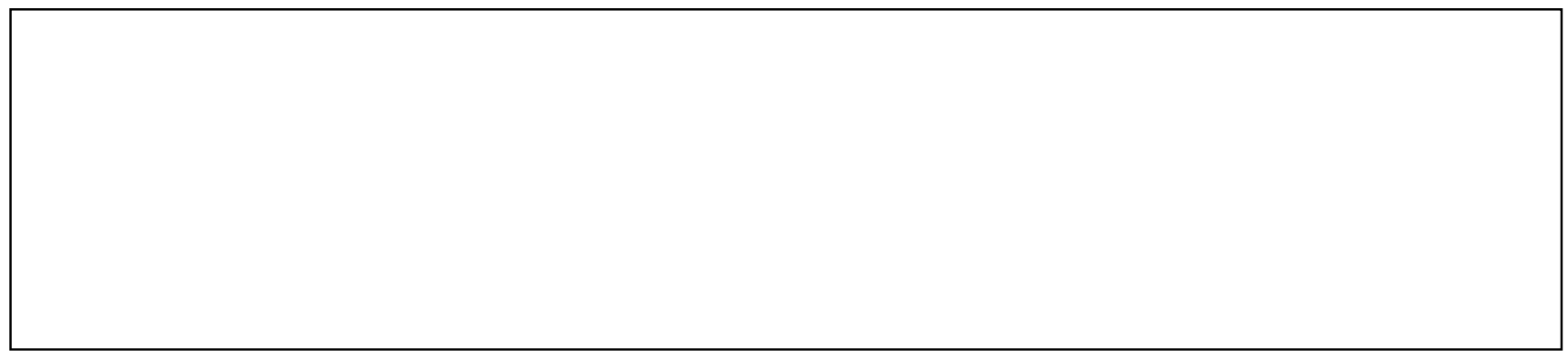

